\title{
ANALYSIS OF INNOVATION SYSTEMS AND ICT POTENTIAL
}

\author{
Tomas Langer ${ }^{1}$ \\ ${ }^{1}$ Technical University of Liberec, Faculty of Economics, Department of Economy Informatics, Studentská 1402/2, \\ Liberec, Czech republic, tomas.langer1@seznam.cz.
}

\begin{abstract}
The following work should briefly outline environmental conditions for innovative entrepreneurs and start-ups in an area of information and telecommunication technologies, conditions of entrepreneurship and doing business easiness in the Czech Republic and comparison with Israel as one of the world innovation leaders with moreover similar size of the population as the Czech Republic. For comparison of overall situation in entrepreneurship and doing business easiness were chosen also another eight developed states with similar size of population. In 2017 was Israel the second most innovative state in the world by the Global Competitiveness Report with own sets of local specific conditions which are settle in the way it can be in useful for other states to take some advices, directions of entrepreneur environment settlement and getting experiences of it. Main areas of this article where is worked out the comparison of the Czech Republic with Israel are gross domestic expenditures on research and development, comparison of structural expenditures of firms on research and development, comparison of overall innovation activity and comparison of innovation systems of Israel and the Czech Republic. Although some studies shows correlations between expansion of ICT and economic growth only in some sectors and in some stage of economy evolution or correlation only if there are also fulfilled other conditions as investments to human resources, in general, studies mostly yield evidence of strong positive correlations between ICT areas and economic growth in modern economies as it participates in the reduction of transaction costs, increases production factors productivity and creates completely new solutions for current problems.
\end{abstract}

Keywords: Innovation, Information and communication technologies, Productivity $* * *$

\section{INTRODUCTION}

\subsection{Importance of ICT for Economy}

Information and communication technologies can be considered from two sides; from production of ICT as supply side and consumption of ICT as demand side.

Production of ICT can be very important for its creation of a substantial part of an economy and can be preferable in some phase of economy development to be supported by state authorities. Considered supply side then must be diversified of quality of production and its size of added value. Also consumption side is important as it responsible for effective functions and elements used by people e.g. Egovernment applications, internet connectivity and coverage etc. There are many synergy co-effects and correlations between both sides and which are important to raise with ICT a sustainable economic growth.

Initial studies that bring together ICT, economy and productivity growth were done by Oliner and Sichel [12] on a global level, followed by series of studies other authors Jorgenson and Stiroh [6] with the study of U.S. economy, Oulton [13] with the study of ICT influence on the economy in the United Kingdom. Majority of authors agree with the correlation between investments to ICT and economic growth [5].

For illustration we can specify following:

- Increasing penetration of $10 \%$ will increase GDP by $1,21 \%$ in developed countries, by $1,38 \%$ in developing countries [10],
- ICT participate on GDP by $5 \%$ in USA, in EU by 3,5 $\%$, in Israel $17 \%$ and in Czech Republic by 4,5\% [15],

- Area of ICT participate on increase of overall productivity by $20 \%$ and $30 \%$ by investments in ICT [11],

- Globally ICT account $6 \%$ of world's economy, 20\% of the economic value of ICT come from ICT industry, developing hardware and goods and $80 \%$ of benefits comes from using ICT [13].

As the area is complex with global links and under turbulent development there are also studies indicating a neutral correlation between ICT and economic growth in some sectors [8]. Nevertheless, generally can be stressed out that slow accepting of new information and communication technologies innovations is the reason for the backwardness of European countries in contrast with Asia or high-tech countries as Israel. European Commission published in 2015 document called Digital Agenda which is one of the seven pillars of Europe 2020 strategy [3]. Digital Agenda focuses on ICT to help with economic progress and innovations as European Commission strongly recommend to focus on ICT development.

ICT pillar concentrate on following topics:

- Achieving the digital single market,

- Enhancing interoperability and standards,

- Strengthening online trust and security,

- Promoting fast and ultra-fast internet access for all,

- Investing in research and innovation,

- Promoting digital literacy, skills and inclusion, 
- ICT-enabled benefits for EU society.

The European Commission targets to digital society which brings benefits from the digital single market. It is meant to be developed and harmonized services which work globally among EU citizens as eGovernment, eHealth, Telemedicine, Smart-cities etc.

\section{COMPARISON OF ICT ENVIRONMENTAL CONDITIONS}

\subsection{Israel Innovation \& ICT Approach}

There are many pieces of knowledge to be reference and analyze about Israel economy way and especially areas that are linked to Israel ICT entrepreneurs and their field of innovation. Behind parts with positive results we could find various reasons; generally Israel's people mentality, business culture as known Israeli approach called chutzpah and all the different challenges that nation is facing regarding compulsory army service where assertiveness and pro-action behaving is a part of casualty. Also there is stable long-term support of state or public research, strong universities support and support of small and medium entrepreneurs with the focus on high-tech start-ups.

Although we admire that information we could also find a few deficiencies and warnings growing up from the narrow specialization.

"A decade ago, Israel had far the highest density of start-ups in the whole world, and draw up more venture capital than anywhere. Today, the entrepreneurial pace feels more like warmish than hot" [7]. Currently Israel authorities proposing and putting in place new ways of supporting entrepreneurs and lower down their business administration.

By examining environment area of SME country which is very similar to Israel with focus on ICT start-ups - USA we pull into those data; approximately 1 million of a new business are set up every year, $40 \%$ of them finish their activity within one year and within 5 years overall collapse $80 \%$ of them - 800000 . From the 200000 remaining businesses within next 5 years stops activity also $80 \%-160$ 000. So it means that till 10 years discontinue $96 \%$ of initial businesses [16].

Behind those numbers are different reasons but a few of them are valid especially for ICT companies and are worth to be highlighted. One of them is "Failure to anticipate or react to competition, technology, or other changes in the marketplace" [9]. This experience from micro range goes around to the macro area of ICT complying what was already spotted about accepting of innovations in ICT and importance of ICT as business and users technology.

\subsection{Innovation Environment Comparison}

State economy with effectively set up state administration, enforceable law and low entrepreneurs barriers can use its full potential to increase life standard and global growth of positive factors, which returns in creation on new innovations and improvements, realizing and commercializing them. In table 1 was chosen 10 countries with similar size of population as the Czech Republic and Israel (+/-20\%). For those countries were obtain data from a branch of World Bank - World Bank Group's Doing Business initiative [17] which brings information about the easiness of doing business - establish and running companies in selected countries. Complete ranking compares 189 countries. By comparing this study with similar studies of organizations Insead [5] and World Economic Forum [18] we are getting similar results.

Demonstrated comparison of chosen countries helps us in getting another relevant data for the study. Israel was ranked by position 53 from 189 countries, which is relatively low position in contrast with above findings of his strongly developed ICT area, top innovative environment and high number of start-ups not only ICT focused. As the reasons can be pointed out the unstable political background in the region which cause limitation of long-term investment and predomination of short and middle term investments, furthermore high corporate taxes and high taxes of highincome persons [15]. The Czech Republic in this comparison achieved better results with 27th place of ranking. Items in which Czech Republic scores considerably better results are foreign trade with 1st place opposite to ranking 58th of Israel, getting electricity, rank 13th against 91st place of Israel, registration of property, rank 32nd against 127th place of Israel and area of tax stress which places the Czech Republic on 53rd place against 103rd of Israel. Israel achieves better results in areas of starting business, property permits and investments protecting. Substantial of problematic parts of Israel are caused by geographical placement of country, historically difficult geopolitical situation and tax burden.

Table 1: Entrepreneurs and business conditions in selected states with similar size Source: Own elaboration based on [17]. 


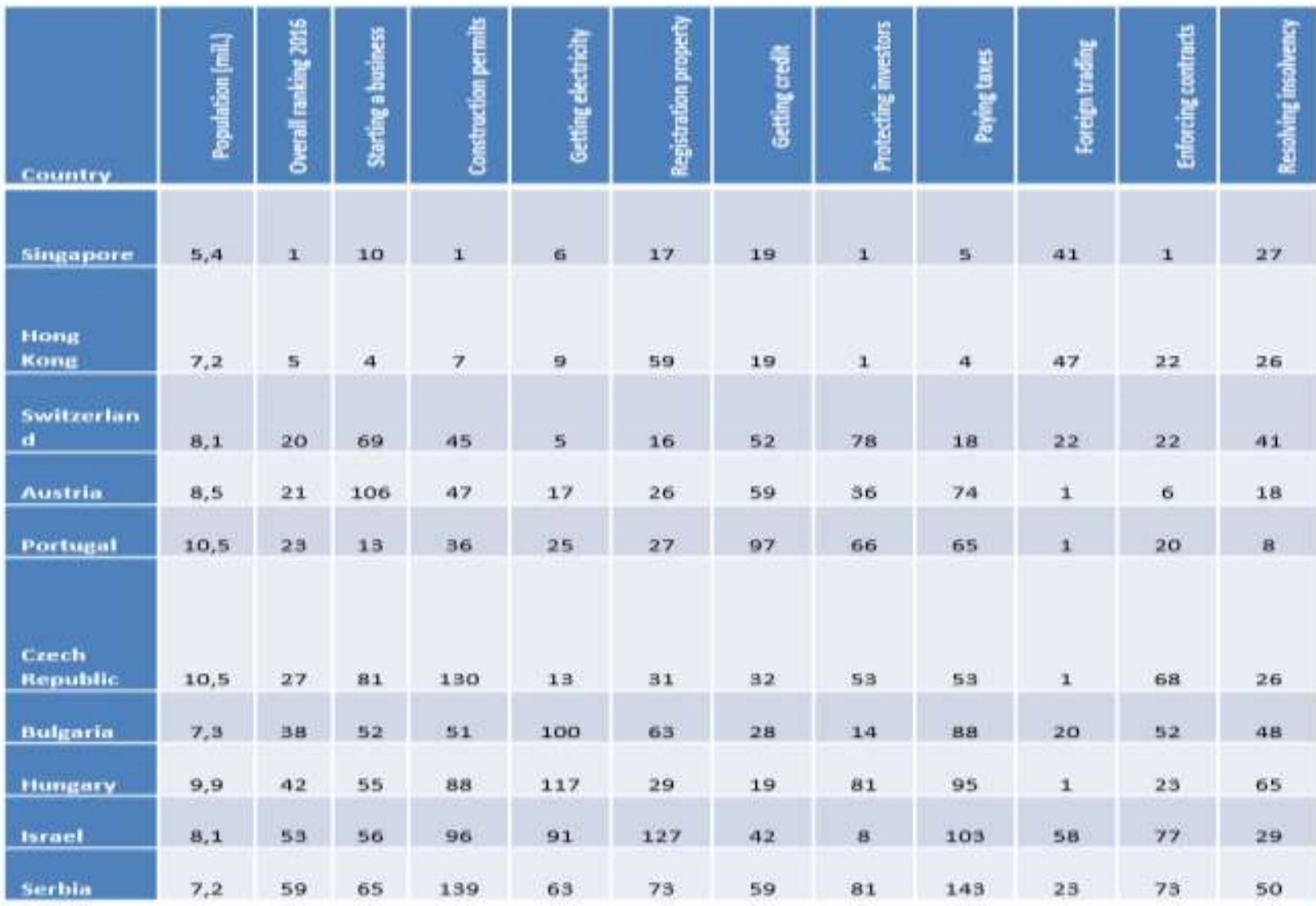

Data on figure 1 illustrate gross domestic expenditures on research and development. Czech Republic's amount of expenditures on R\&D is long-term staying behind of OECD countries average. In closer comparison were in 2015 gross domestic expenditures on research and development 1,947 $\%$ of GDP, in contrast to expenditures of compared country Israel - 4,253 \% of GDP. In the period from 2007 to 2013 raised expenditures significantly almost by $40 \%$ in the Czech Republic. However, in recent period counted from the year 2013 was growing tendencies slowing down and by the year 2015 expenditures slightly decreased from 1,973\% to $1,947 \%$ of GDP. Germany as the neighbor and the biggest export partner for the Czech Republic, strongly focused on innovations and technology development has expenditures of $2,927 \%$ of GDP. OECD countries have average expenditures on R\&D 2,38 \% of GDP.

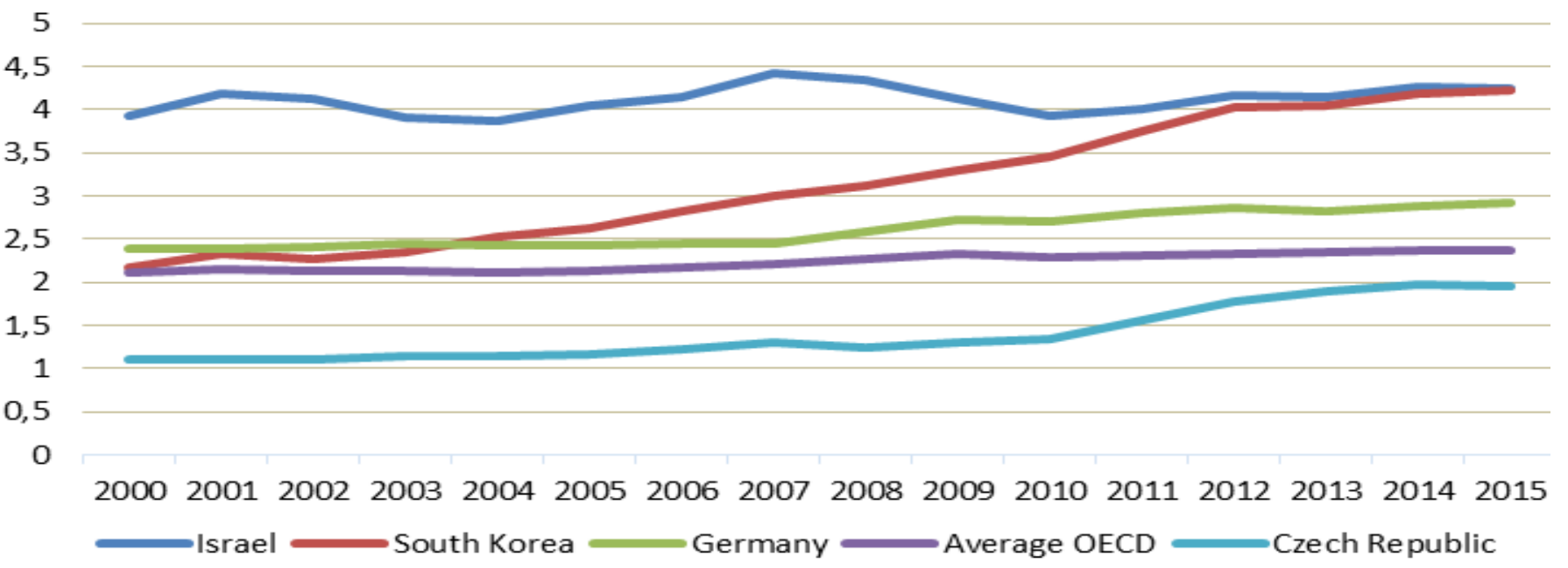

Fig -1: Gross domestic expenditures on R\&D, (\%), 2000 - 2015. Source: Own elaboration based on [11]. 
Figure 2 demonstrates innovation activity by structural expenditures of firms on $R \& D$ and compare the Czech Republic and Israel. On figure can be seen that in the segment of services are expenditures in Israel on R\&D 71,4 $\%$ of total expenditures compared to $38,2 \%$ expenditures in the Czech Republic. Also segment high-tech has a higher representation in Israel - 20,1\% compared to $7,6 \%$ expenditures in the Czech Republic. The Czech Republic has a higher share in non-resource based manufacturing industries which share is equal to $54,7 \%$ compared to 25,6 $\%$ in Israel. Important is also information in the segment of SMEs, where expenditures in Israel are equal to $60,1 \%$ compared to $45,7 \%$ share in the Czech Republic.

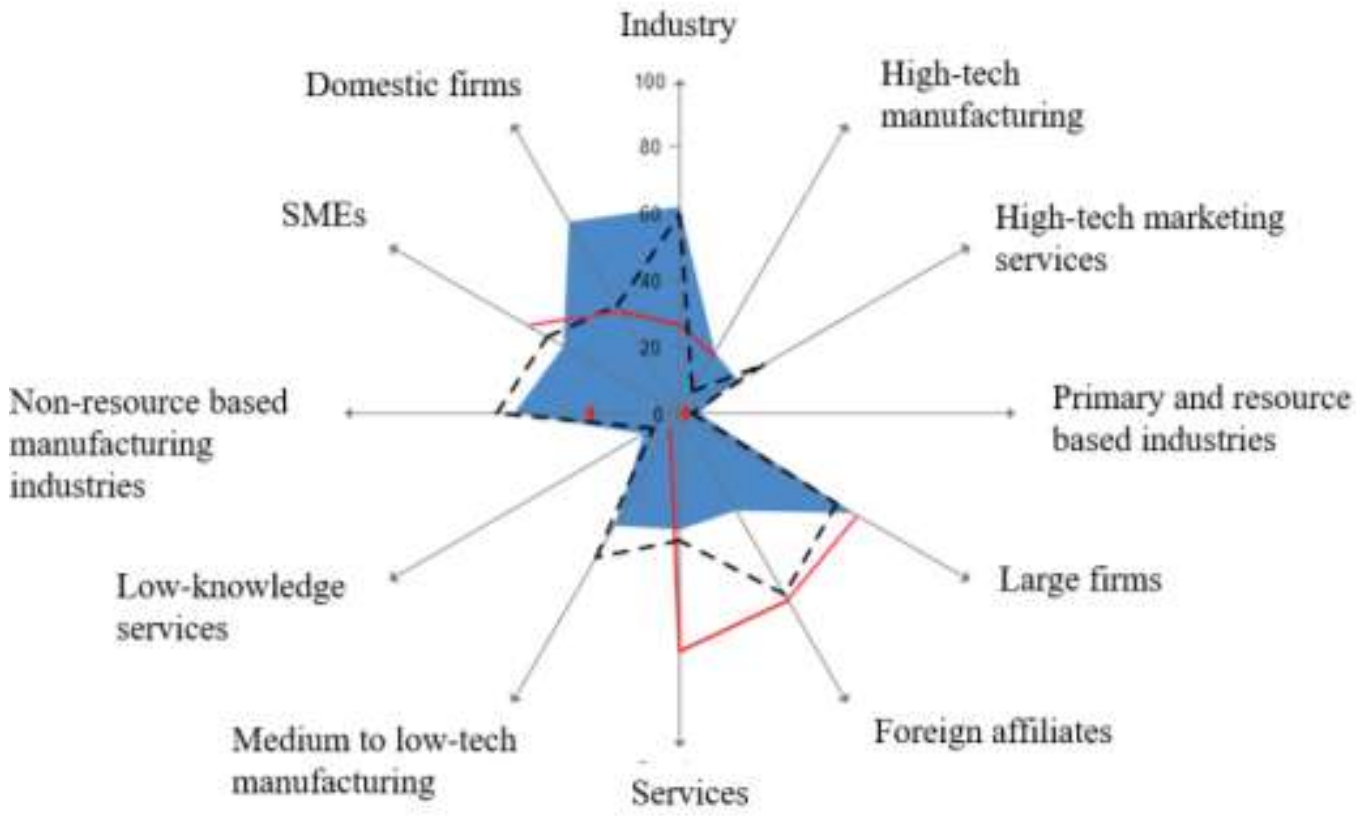

Fig -2: Comparison of structural expenditures of firms on R\&D in Czech Republic and Israel. Source: Own elaboration based on $[1,2]$.

Figure 3 illustrates combination of data from Czech Statistical Bureau and Central Bureau of Statistics Israel [2, 1]. This comparison demonstrates innovation activity by the size of entrepreneurs in both analyzed countries. Comparison suggests us almost double innovation activity in Israel - $83 \%$ firms with some kind of innovation activity in Israel and $42 \%$ innovative firms in the Czech Republic. In the segment of large firms the difference is not as significant - $77 \%$ of large firms innovate in the Czech Republic compared to $93 \%$ of large firms which innovate in Israel. One of the reasons of the considerable difference is more stable baseline of material, financial and human resources by large firms for innovation purposes. In the segment of medium firms is difference $59 \%$ in the Czech Republic compared to $88 \%$ in Israel. The greatest difference is in segment of small entrepreneurs where in Israel innovate 85 $\%$ from total amount of entrepreneurs in the segment and in the Czech Republic only $35 \%$. One of the main reasons behind those results is stable state support of new entrepreneur's projects, startup incubators, material and financial subsidies followed strong support of private sphere. In the Czech Republic was innovation support negatively influenced by the financial crisis, when companies reduced their investments to innovative solutions especially to non-technical innovations and solutions. 


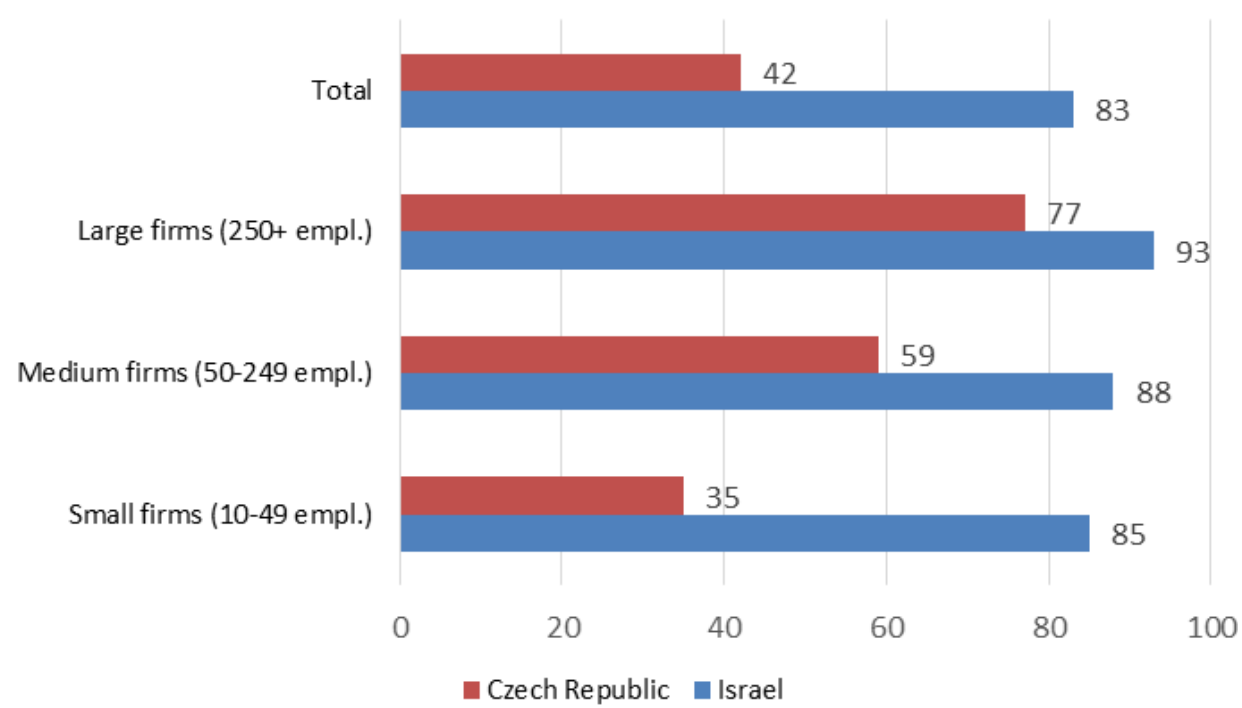

Fig -3: Comparison of innovation activity Czech Republic vs. Israel, 2012-2014. Source: Own elaboration based on [1, 2].

Figure 4 shows the comparison of chosen criteria innovation system the Czech Republic and Israel. The comparison is based on data from databases of OECD, Czech Statistical Bureau and Central Bureau Statistics of Israel [11, 2, 1].
Bottom and top is represented by lowest/highest 5 values and figure are divided by its median on the bottom half and upper half.

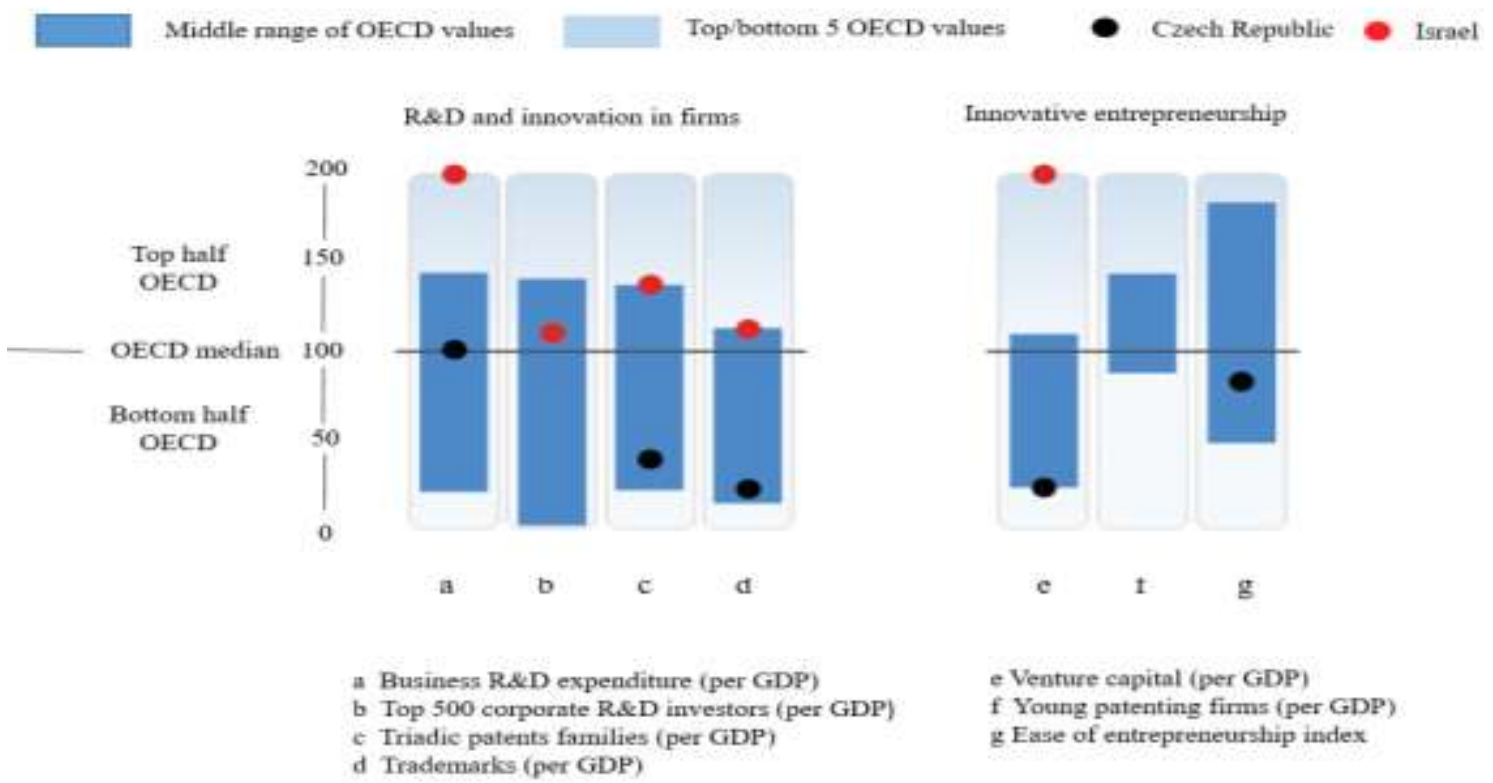

Fig -4: Comparison of national innovation systems Czech Republic vs. Israel - 2014. Source: Own elaboration based on [1, 2].

The left part of figure 12 is devoted to companies' innovations and R\&D. Column (a) compares R\&D expenditure which was already described above. Column (c) indicate a difference in a number of registered patents which are marked as triadic. Among triadic patents belongs patents that are registered by European Patent Office (EPO), the
United States Patent and Trademark Office (USPTO) and the Japan Patent Office (JPO) [13]. It's obvious that Israel with value 3,5 registered patents per 1 bio. USD belongs among upper half countries in contrast to placed Czech Republic in the bottom half of OECD countries with value 0,14 registered patents per 1 bio. USD. The similar is 
relevant for column (d) where the compared number of registered trademarks is. Israel reach the value of 1,33 registered trademarks per 1 bio. USD opposite to the Czech Republic with 0,24 registered trademarks per 1 bio. USD.

In the right part of the figure are data corresponding to entrepreneur's innovations. Column (e) shows the amount of risk capital invested to start-ups. In this area has Israel in the long-term the highest rate of risk capital with 0,38\% GDP. Czech Republic with value of $0,006 \%$ GDP belongs to OECD countries with the low volume of risk capital and lack of investors willing to support high-risk projects. Column (g) represent the index of entrepreneurs' environment. In this respect the Czech Republic brings better results. In scale of $0-6$ where 0 stands for strong entrepreneurs barriers and 6 for low, reach Czech Republic $-4,18$ and Israel 3,5.void hyphenation at the end of a line. Symbols denoting vectors and matrices should be indicated in bold type. Scalar variable names should normally be expressed using italics. Weights and measures should be expressed in SI units

\section{CONCLUSION}

Information and communication technologies are an instrument that can bring new effective ways and solutions to the economy and social environment. Their support on a national level by a maintenance of correct business atmosphere with the proper legal environment, supporting public research and development, subsidizing of new entrepreneurs ideas and start-ups is a proper way how to create and increase national wealth.

ICT is a resource of economic growth on side of demand and side of supply. Is it necessary to distinguish which site is preferable to support by the government. The Czech Republic strongly supported individual ICT producers of hardware components resulting to be 9th biggest ICT exporter in the world. Unfortunately, this counts only assembling imported parts which results low added value of manufacturing and offering low-income jobs. By looking to the close history we can see slightly better support be increasing state expenditure on R\&D although still below the average of OECD countries and far below the top technology and innovative countries as Israel is. It is very questionable why in the Czech Republic in the period of the financial crisis where expenditures on $\mathrm{R} \& \mathrm{D}$ growing but recently in the overall world economic prosperity are expenditures constant moreover slightly decreasing. Low expenditures on R\&D, tiny support of small entrepreneurs and innovative start-ups with increasing administrative burden is the reason why results in comparison of innovation activity in the Czech Republic are far behind results from Israel.

The Czech Republic can improve economic growth instead of supporting a new investment of companies producing low added value goods supporting by different types of subsidies public $R \& D$ and new innovative start-ups to become the high-tech country. As a country for comparison was chosen Israel which is an innovative leader in high-tech ICT industry, growing correct business environment by rising up start-ups and supporting them what generally makes country economically strong with a modern economy and business structure. We also demonstrated there are some areas which needs to be improved or which are specific and related to the geographical and geopolitical situation. At beginning of conclusion part of article was stated why could be results and directions from this study important. Also is necessary to point out that for the topic of this width and complexity is necessary to significantly extent study to cover more interactions which co-exist together and forms whole economy environment.

\section{ACKNOWLEDGEMENT}

The authors would like to thank all colleagues and students who contributed to this study. We are grateful to doc. Ing. Klára Antlová, Ph.D. for her collaborations, and to our Research Assistant, Ing. Petra Matoušková, who assisted with recording and transcription.

\section{REFERENCES}

[1] The Central Bureau of Statistics, Israel: Business Innovation Survey, <www.cbs.gov.il/reader/cw_usr_view_SHTML?ID= 426>.

[2] The Czech Statistical Bureau: Inovační aktivity podniků v ČR - 2012 až 2014, $<$ https://www.czso.cz/csu/czso/veda-vyzkum-ainovace-publikace $>$.

[3] European Commission: Europe 2020 Strategy: The Digital Agenda, The Directorate-General for Communications Networks, Content and Technology, $<$ https://ec.europa.eu/digital-single-market/en/europe2020-strategy>.

[4] Indjikian, Rouben a Siegel, Donald S.: The impact of investment in it on economic performance: Implications for developing countries. World Development, Geneva (2015).

[5] INSEAD - The Business School for the World. INSEAD European Competitiveness Initiative: Global Competitiveness Index. $<$ https://www.insead.edu/news/2017-global-talentcompetitiveness-index-davos $>$.

[6] Jorgenson, D., Stiroh, K.: Information Technology and Growth. American Economic Review, (1999).

[7] Lagorio, Ch.: What Ever Happened to Start-up Nation?,

<http://www.inc.com/articles/201105/ whathappened-to-israeli-entrepreneurship.html>

[8] Machková, H.: International marketing, Strategic trends a Practical examples. Grada Publishing, Prague (2015).

[9] Mason, Moya K.: What Causes Small Businesses to Fail?, New York (2011).

[10] The Ministry of Trade and Industry of the Czech Republic: State politic in e-communication - Digital 
Czech, The Ministry of Trade and Industry of the Czech Republic, $<$ http://download.mpo.cz/get/43273/48548/573486/pr iloha001.pdf>.

[11] OECD: Measuring Digital Economy: A New Perspective, OECD Publishing, $<$ http://www.oecd.org/sti/measuring-the-digitaleconomy-9789264221796-en.htm>.

[12] Oliner, S., Sichel, D.: The Resurgence of Growth in the Late 1990s: is Information Technology the Story?. Journal of Economic Perspectives, (2001).

[13] Oulton, N.: ICT and productivity growth in the UK. Oxford Review of Economic Policy, (2002).

[14] Pilat, D.: The ICT productivity paradox: Insights from micro data. OECD Economic Studies, London (2004).

[15] UNESCO: Global Observatory of Science, Technology and Innovation Policy Instruments, Mapping Research and Innovation, $<$ http://www.unesco.org/new/en/naturalsciences/science-technology/sti-policy/globalobservatory-of-policy-instruments>.

[16] The United States International Trade Commission: Small and Medium Sized Enterprises: Overview of Participation in U.S. Exports. $<$ https://www.usitc.gov/publications/332/pub4125.pd $\mathrm{f}>$.

[17] The World Bank - World Bank Group's Doing Business initiative: The Doing Business - Measuring Business Regulations. <http://www.doingbusiness.org/rankings>.

[18] The World Economic Forum: The Global Competitiveness Report $2017 \quad$ - 2018. $<$ https://www.weforum.org/reports/the-globalcompetitiveness-report-2017-2018>. 